REVISTA TóPICOS EdUCACIONAIS

Revista do Programa de Pós-Graduação em Educação

da Universidade Federal de Pernambuco (UFPE)

\title{
POLÍTICA Y CORPOREIDAD. ELEMENTOS COSMPOLITAS EN EL PENSAMIENTO POLÍTICO DE TH. HOBBES. ${ }^{1}$ POLICY AND CORPOREITY. COSMPOLITE ELEMENTS IN THE POLITICAL THOUGHT OF TH. HOBBES.
}

\author{
José Manuel Panea Márquez ${ }^{2}$ \\ Universidad de Sevilla - España
}

\begin{abstract}
Resumen: Tomando como punto de partida la reflexión de Jean Améry sobre la tortura, analizamos la importancia del cuerpo como horizonte y como límite en el pensamiento político de Hobbes. Este asunto afecta a la cuestión de la legitimación del poder, lo que se espera de él, ya al problema de la obediencia. Además, en la medida en que compartimos universalmente una corporeidad común, encontramos aquí las bases para una filosofía política en clave cosmopolita.
\end{abstract}

Palabras clave: Améry, Hobbes, educación política, corporeidad, obediencia, paz, cosmopolitismo.

\begin{abstract}
Taking as a starting point Jean Améry's reflection on torture, we analyze the importance of the body as a horizon and as a limit in Hobbes' political thought. This issue affects the question of the legitimation of power, what is expected of it, and the problem of obedience. Furthermore, insofar as we universally share a common corporeity, we find here the bases for a political philosophy in a cosmopolitan key.
\end{abstract}

Key words: Améry, Hobbes, political education, corporeity, obedience, peace, cosmopolitanism.

1. Introducción: violencia, confianza, contrato.

Somos ciudadanos del mundo. Y lo somos de un mundo compartido: aquel que nos enlaza y hermana sólo por habitar un mismo cuerpo. Queremos insistir en la importancia política del cuerpo en Hobbes. Y ello porque este no sólo será un ingrediente universal, más allá de cualquier particularismo de la índole que sea, que nos vincule a todos por igual, sino que constituye, además, un horizonte y un límite para la acción del soberano, problematizando, al mismo tiempo, el concepto de obediencia y desobediencia.

\footnotetext{
${ }^{1}$ Este trabajo se enmarca dentro de las actividades desarrolladas por el Proyecto de Investigación: "La cultura jurídica cosmopolita y sus desarrollos contemporáneos: límites y posibilidades en tiempos de crisis". (PY20_00980), del Plan Andaluz de Investigación, Desarrollo e Innovación (PAIDI, 2020), de la Junta de Andalucía (España).

${ }^{2}$ Universidad de Sevilla. E-mail: jmpanea@us.es. http://orcid.org/0000-0001-6261-0582.
}

Revista Tópicos Educacionais, Pernambuco, v. 27, n. 02, p. 182-206, 2021. ISSN: 2448-0215. https://periodicos.ufpe.br/revistas/topicoseducacionais/index DOI: 10.51359/2448-0215.2021.251832 


\section{REVISTA TóPICOS EDUCACIONAIS \\ Revista do Programa de Pós-Graduação em Educação da Universidade Federal de Pernambuco (UFPE)}

Narrando la violencia que sufrió a mano de los nazis, Jean Améry da cuenta de los excesos de los que fue víctima en una lacónica afirmación: lo real en la tortura siempre desborda a lo imaginario, siendo el acontecimiento más atroz que un ser humano puede conservar en su interior (AMÉRY, 2001, 83).

Un efecto inmediato de la tortura, nos dice Améry, es la conciencia del desamparo, pues el prisionero piensa que harán con él lo que se les antoje. Con el primer golpe no sólo pierde su dignidad humana, aunque sea difícil dar una definición precisa de la misma, sino algo que para Améry no es menos esencial, a saber, pierde la confianza en el mundo y en los otros:

Sin embargo, estoy seguro de que ya con el primer golpe que se le asesta pierde algo que tal vez podríamos denominar provisionalmente confianza en el mundo. En la confianza en el mundo intervienen varios supuestos: la fe irracional en el férreo principio de causalidad, injustificable desde un punto de vista lógico, por ejemplo, o la convicción, igualmente ciega, sobre la validez de las inferencias inductivas. Pero el supuesto más importante de esta confianza -y el único relevante en nuestro contextoes la certeza de que los otros, sobre la base de contratos sociales escritos o no, cuidarán de mí, o mejor dicho, respetarán mi ser físico y, por lo tanto, también metafísico. (...).

Con el primer golpe, no obstante, se quebranta esa confianza en el mundo. El otro contra el que me sitúo físicamente en el mundo y con el que sólo puedo convivir mientras no viole las fronteras de mi epidermis, me impone con el puño su propia corporalidad. Me atropella y de ese modo me aniquila. Se parece a una violación, a un acto sexual sin el consentimiento de una de las partes (AMÉRY, 2001, 90-91).

Lo interesante de Améry es que no ha pasado por alto cuál es el reverso de la violencia: el acuerdo posible, y la confianza que aquel encarna. En efecto, no ha dudado, al darnos su testimonio de víctima de la violencia, en subrayar todo lo que hay en juego en el contrato social, pues se abre la esperanza de un auxilio; tenemos la certeza de ayuda; recuperamos la confianza en el mundo, tan esencial para animales y humanos:

La esperanza de socorro, la certeza de ayuda forman parte, en efecto, de las experiencias fundamentales del ser humano y sin duda también del animal, como han expuesto muy convincentemente el viejo Kropotkin, que hablaba de la ayuda mutua en la naturaleza, y el moderno etólogo Lorenz. La expectativa de ayuda pertenece a los elementos constitutivos de nuestra psique tanto como la lucha por la existencia (AMÉRY, 2201, 91).

Revista Tópicos Educacionais, Pernambuco, v. 27, n. 02, p. 182-206, 2021. ISSN: 2448-0215. https://periodicos.ufpe.br/revistas/topicoseducacionais/index DOI: 10.51359/2448-0215.2021.251832 


\section{REVISTA TóPICOS EduCACIONAIS \\ Revista do Programa de Pós-Graduação em Educação da Universidade Federal de Pernambuco (UFPE)}

La etimología de torturar, del latín torquere, es bien elocuente: luxar, contorcer, dislocar. Y el desamparo es mayor cuanto más conscientes somos de lo arbitrario e ilimitado de la violencia. Por eso, dirá Améry, la víctima no sufre la tortura como un mal trivial, sino como la intervención de un poder soberano, casi sagrado, como sugirió también Bataille (1993, p. 228s; 2000, p. 22s), para quien el sadismo no es una patología sexual, sino existencial: implica la negación radical del otro, de la sociedad, del mundo. En la negación del otro, en su aniquilación, el sádico hace pleno ejercicio de su soberanía. Pero dejemos que sea el propio Améry quien explique la aterradora disolución del yo en mera cosa cuando está bajo el poder omnímodo del torturador:

Está en sus manos provocar gritos de dolor y de agonía, es señor de la carne y del espíritu, de la vida y de la muerte. Así la tortura supone una inversión absoluta del mundo social: en éste podemos vivir sólo si reconocemos la vida también del prójimo,si dominamos el impulso expansivo del yo, si mitigamos su sufrimiento. Pero en el mundo de la tortura, el hombre subsiste sólo en la destrucción del otro. Una ligera presión con la mano provista de un instrumento de suplicio basta para transformar al otro, incluida su cabeza, donde tal vez se conservan las filosofías de Kant, Hegel y las nueve sinfonías completas y El mundo como voluntad y representación, en un puerco que grita estridentemente de terror cuando lo degüellan en el matadero (AMÉRY, 2001, p. 100-101).

Estas reflexiones, de quien vivió en sus carnes la tortura nazi más atroz (SARAVIA, 2016), no son meramente un testimonio de primera mano; son la constatación más angustiosa y cruda de que gran parte de lo que entendemos por problemas filosóficos son cuestiones que atañen directamente al corazón de nuestras vidas. Por ello, los comentarios de Améry sobre la violencia, o la tortura; la pérdida de la dignidad, el desamparo, así como su consideración positiva del contrato social, nos predisponen magistralmente para la toma de conciencia del valor de lo político, y de la importancia de asumir nuestra corporeidad en tanto que realidad primera, cuyas demandas habrá que gestionar del modo más justo o adecuado; pues será a partir del descubrimiento de nuestra corporeidad común, y del reconocimiento de su dimensión política, como mejor cabrá entender su imbricación con el mundo natural y social. Y en tal sentido, quisiéramos aprovechar la ocasión que este espacio nos brinda para hacer justicia a un autor que ha sabido, ejemplarmente, tomar conciencia de esta realidad humana, natural y política a un tiempo, y de los peligros que la acechan, así como de la importancia de que los hombres lleguen inexcusablemente a acuerdos para superar la violencia. Nos estamos refiriendo a Thomas Hobbes.

Revista Tópicos Educacionais, Pernambuco, v. 27, n. 02, p. 182-206, 2021. ISSN: 2448-0215.

https://periodicos.ufpe.br/revistas/topicoseducacionais/index

DOI: $10.51359 / 2448-0215.2021 .251832$ 


\section{REVISTA TóPICOS EdUCACIONAIS \\ Revista do Programa de Pós-Graduação em Educação \\ da Universidade Federal de Pernambuco (UFPE)}

\section{De la humana y común corporeidad como horizonte y límite al ejercicio del poder soberano.}

Las fronteras de mi cuerpo son las fronteras de mi yo ${ }^{3}$

Jean Améry

Hablar de Hobbes (1588-1679) es, sin lugar a dudas, hablar de uno de los más destacados pensadores de la filosofía moral y política de todos los tiempos. Pero quisiéramos acercarnos a un aspecto que nos parece esencial: ¿qué papel juega nuestra indigente, finita, doliente y mortal condición ¿De qué modo lo tiene presente Hobbes? ¿Cómo afecta nuestra corporeidad a la decisiva cuestión de la obediencia y la desobediencia al poder? ¿Y qué razones cabe encontrar en Hobbes contra la violencia?

Siendo el problema de la obediencia al poder un tema muy antiguo, en el caso de Hobbes nos atreveríamos a decir que es la cuestión por excelencia en su obra teórica. Y ello, probablemente, por su obsesión de erradicar el caos, sinónimo de violencia, destrucción y muerte, ejemplificado en Behemoth; conceptos a los que hay que oponer los de poder soberano, ley, racionalidad, Estado, y paz, que sólo Leviatán puede garantizar y preservar, habida cuenta de cómo es el mar de pasiones que se agitan en lo más profundo del corazón humano. De manera que el problema de la ley, y de la obediencia a la misma, pasará a un primer plano. Y las razones que para ello esgrimirá son de todos bien conocidas, pudiendo resumirlas en una sola: su intención de preservar la paz como conditio sine qua non para que pueda darse la vida en su más amplio y pleno sentido ${ }^{4}$.

\footnotetext{
${ }^{3}$ Améry (2001, p. 91).

${ }^{4}$ Basta para entender a Hobbes el siguiente texto en el que, ejemplarmente, expone a qué queda reducida la vida en tiempos de guerra: "Por tanto, todas las consecuencias que se derivan de los tiempos de guerra, en los que cada hombre es enemigo de cada hombre, se derivan también de un tiempo en el que los hombres viven sin otra seguridad que no sea la que les procura su propia fuerza y su habilidad para conseguirla. En una condición así, no hay lugar para el trabajo, ya que el fruto del mismo se presenta como incierto; y, consiguientemente, no hay cultivo de la tierra; no hay navegación, y no hay uso de productos que podrían importarse por mar; no hay construcción de viviendas, ni de instrumentos para mover y transportar objetos que requieren la ayuda de una fuerza grande; no hay conocimiento en toda la faz de la tierra, no hay cómputo del Revista Tópicos Educacionais, Pernambuco, v. 27, n. 02, p. 182-206, 2021. ISSN: 2448-0215. https://periodicos.ufpe.br/revistas/topicoseducacionais/index
} DOI: 10.51359/2448-0215.2021.251832 


\section{REVISTA TóPICOS EDUCACIONAIS \\ Revista do Programa de Pós-Graduação em Educação \\ da Universidade Federal de Pernambuco (UFPE)}

Pero su justificado interés por el tema de la obediencia no le hará descuidar las posibles razones para la desobediencia. En cualquier caso, hay que subrayar que Hobbes si bien combatió siempre la falta de comprensión de los ciudadanos acerca de la necesidad que tiene la ley de ser obedecida $^{5}$, subrayando la importancia de la educación política de la ciudadanía, otro tanto hizo con las posibles alegaciones o excusas, amparadas en la cuestión de si la ley tenía o no por encima suya alguna instancia de orden superior que la sometiera a condiciones en cuanto a su cumplimiento $^{6}$. Porque, ciertamente, desde el punto de vista de nuestro autor, la desobediencia, salvo en las excepciones que él mismocontemplará, genera una fuente inagotable de conflictos y de inestabilidad social, la cual terminará dando paso a graves enfrentamientos y guerras civiles. La paz social se verá seriamente comprometida, si ponemos en tela de juicio el principio de obediencia a la ley. Y esto lo sabía perfectamente Hobbes, quien tendrá a Behemoth bien presente ( el monstruo de la destrucción y la devastación, excelentemente ejemplificado en la guerra civil inglesa) ${ }^{7}$ cuando siente las bases para la instauración de un Estado racional, que organice y posibilite la convivencia pacífica.

Reducir a su mínima expresión la desobediencia al soberano y a la ley, al ser aquélla la fuente primera de conflictividad social, será un objetivo prioritario en Hobbes (HERMOSA, 2008, p. 81s; 2009, p. 49s). Y, sin embargo, esta preocupación por la paz social, este interés suyo por el orden, en definitiva, jurídica y políticamente asegurado, posibilitador del comercio, de las artes, del

tiempo; no hay artes; no hay letras; no hay sociedad. Y lo peor de todo, hay un constante miedo y peligro de perecer con muerte violenta. Y la vida del hombre es solitaria, pobre, desagradable, brutal y corta." (HOBBES, 1989, XIII, p. 107-108).

${ }^{5}$ Son numerosas las referencias en su obra al papel que tienen las Universidades, y a las doctrinas que deben impartir, o, mejor dicho, que tendrían que evitarse a toda costa. En concreto, será la doctrina de la desobediencia civil su auténtico caballo de batalla. Y toda su filosofía política podría leerse en esta clave, ya que de la desobediencia civil se extrae como consecuencia, para Hobbes, el desmantelamiento del orden social, con el nefasto resultado del mayor de todos los males: la muerte y su mejor aliada, la guerra. Pero para un racionalista como Hobbes, el problema no es tanto la discrepancia teórica, sino su utilización no serena en aras de la perturbación de la paz social. Una buena muestra de que la censura no iría tanto contra el avance de la razón, sino más bien contra su utilización cuando pone en peligro la paz social es, sin duda, la que encontramos en El ciudadano (HOBBES, 1993, VI, p. 59-60). Y un texto ejemplar nos parece el siguiente: "Un Estado puede forzar a la obediencia, pero no convencer del error, ni alterar la mente de quienes creen tener más razón." (HOBBES, 1992a, p. 82).

${ }^{6}$ El propio Hobbes se refiere a este problema cuando escribe: "Si no hubiese habido primero la opinión, extendida por la mayor parte de Inglaterra, de que estos poderes estaban divididos entre el rey y los lores, y la Cámara de los Comunes, el pueblo no hubiera llegado nunca a dividirse y a caer en la presente guerra civil, primero entre los que discrepaban en política, y después entre los que disentían acerca de la libertad de religión.” (HOBBES, 1989, XVIII, p. 152).

${ }^{7}$ Para este asunto remitimos al amplio desarrollo que encontramos del mismo en su Behemoth. En este sentido, Hernández (2002, p75s), donde se expone magistralmente el contexto histórico y el debate filosófico-político que enmarcan la génesis del Leviatán.

Revista Tópicos Educacionais, Pernambuco, v. 27, n. 02, p. 182-206, 2021. ISSN: 2448-0215.

https://periodicos.ufpe.br/revistas/topicoseducacionais/index

DOI: 10.51359/2448-0215.2021.251832 
Revista TóPICOS EduCaCionais

Revista do Programa de Pós-Graduação em Educação

da Universidade Federal de Pernambuco (UFPE)

pensamiento y del bienestar de la ciudadanía (HOBBES, 1989, XIII, p. 107s), a la vez que sus recelos para con la desobediencia, no implicará ni que la ley tenga que ser obedecida sin más (es decir, sin imponer ningún tipo de condiciones $)^{8}$, ni que el soberano carezca de restricciones en el ejercicio del poder $^{9}$, ni que los individuos no puedan alegar circunstancias para así negar la obediencia debida al soberano, y, por tanto, para desobedecer legítimamente sus mandatos. Como sostiene Isaiah Berlin al respecto:

Pero Hobbes no dice que todas las leyes tengan que ser duras. Esto es un error. Aunque se lo haya interpretado así, Hobbes no quería ni crueldades ni opresión. Lo que quería eran leyes rigurosas, pero sólo lo absolutamente imprescindibles para mantener el orden público (BERLIN, 1993, p. 90).

A lo que añadiríamos nosotros, que no sólo para mantener el orden, sino para que los ciudadanos puedan vivir bien. Y así lo expresó rotundamente: salus populi suprema lex (HOBBES, 1993, XIII, p. 112). Porque, sin lugar a dudas, Hobbes es un decidido defensor de la razón. Pero

\footnotetext{
${ }^{8}$ Estamos, sin duda, ante un asunto polémico, porque con facilidad se le atribuye al Soberano un poder arbitrario. Pero no es esto lo que tiene nuestro autor en mente cuando escribe: "Es responsabilidad del soberano hacer buenas leyes. Pero ¿qué es una buena ley? Cuando digo una buena ley, no quiero decir una ley justa, pues ninguna ley puede ser injusta. La ley es hecha por el poder soberano, y todo lo que es hecho por este poder es corroborado por el pueblo, y éste lo toma como suyo. Y lo que cada súbdito acepta como propio de esta manera, no puede ser calificado de injusto por nadie. Sucede con las leyes del Estado lo mismo que con las reglas del juego: que lo que todos los jugadores acuerdan entre ellos, no es injusticia para ninguno. Una buena ley es aquello que es necesario para el bien del pueblo, y, además, claro e inequívoco". (HOBBES, 1989, XXX, p. 276). Pero, además de tener la ley que estar orientada clara e inequívocamente al bien del pueblo -es decir, sin que pueda prestarse a argucias retóricas-, Hobbes hace una distinción muy interesante entre justicia y equidad. En efecto: "En una ley estatutaria, hecha por hombres, puede muy bien encontrarse iniquidad pero no injusticia" (HOBBES, 1992b, p. 24). Para Hobbes no hay ley injusta porque la justicia no es algo anterior a la ley, como si fuera un criterio para juzgarla; la ley es anterior a la justicia, por eso la ley es el criterio de lo justo. Pero esto no significa que toda ley esté exenta de examen racional, porque la ley, si no es de conformidad con los dictados de la razón, estaría promoviendo la iniquidad, y no sería una buena ley. Dicho en otras palabras, no hay ley injusta para Hobbes, pero esto no significa que toda ley sea de hecho una buena ley, es decir, que sea un espejo donde pueda reconocerse la equidad y el resto de los dictados racionales.

${ }^{9}$ Basta con leer el siguiente pasaje donde Hobbes habla de cómo el soberano ha de someterse a los dictados de la razón (ley natural): "Es verdad que todos los soberanos están sujetos a las leyes de naturaleza, pues dichas leyes son divinas y no pueden ser derogadas por ningún hombre ni por ningún Estado". (HOBBES, 1989, XXIX, p. 259-260). No nos parece admisible, pues, decir como hace N. Bobbio, que el soberano puede violar las leyes naturales; más aún, para Bobbio, el poder del soberano es ilimitado tanto con respecto a las leyes naturales, como respecto al derecho de los súbditos. Y es que, en definitiva para Bobbio, “(...) una vez erigido el Estado, las leyes naturales no tienen razón de ser”. (BOBBIO, 1990, p. 177). Pero este comentario no puede dar cuenta de numerosos textos en los que Hobbes intenta convencernos de que el soberano ha de procurar sintonizar la ley positiva con los dictados de la razón, o ley natural. Es cierto que, como hemos visto, no hay ley injusta, según Hobbes, porque al igual que con las reglas del juego, lo que acuerdan los jugadores no es injusto para ninguno, según nos decía nuestro autor en un texto citado más arriba. Pero ello no implica que la ley no pueda carecer de equidad, y esto la convierte en una mala ley, sencillamente porque no ha respetado los dictados de la razón y no ha buscado el bien del pueblo, como ya hemos visto. Por otra parte, el tema es muy complejo para ser tratado aquí. Baste la referencia, por ejemplo a Leo Strauss, para quien el derecho hobbesiano estaría a caballo entre los principios estrictamente morales (ley natural tradicional) y los principios puramente naturales, como el placer o la utilidad (STRAUSS, 2006, p. 11). Revista Tópicos Educacionais, Pernambuco, v. 27, n. 02, p. 182-206, 2021. ISSN: 2448-0215. https://periodicos.ufpe.br/revistas/topicoseducacionais/index
} DOI: $10.51359 / 2448-0215.2021 .251832$ 


\section{REVISTA TóPICOS EDUCACIONAIS \\ Revista do Programa de Pós-Graduação em Educação \\ da Universidade Federal de Pernambuco (UFPE)}

no de una abstracción, de una entelequia incomprensible, sino de una razón encarnada. Tal defensa, pues, se verá plasmada en el ámbito político, donde será esta ${ }^{10}$, y no la barbarie desatada por el irresoluble conflicto de las pasiones, quien asuma el principal protagonismo para preservar la propia vida frente a toda amenaza externa. Y no sólo la propia vida, sino la de todos, al compartir una misma naturaleza y, por tanto, los derechos anclados en este hecho incontestable.

Para nuestro autor, como lo ha destacado muy bien Norberto Bobbio, la vida es el summum bonum (BOBBIO, 1990, p. 53). Y este dato conviene no olvidarlo, pues en tanto en cuanto el ser humano es un cuerpo viviente, y no una entelequia; y en la medida en que tal realidad supone la encarnación de la razón en una corporeidad común ${ }^{11}$, universalmente compartida, dicha encarnación posibilitará determinar el ámbito de lo razonable $y$ de lo legítimo. Tal será, pues, el fundamento de la igualdad de derechos entre los hombres. Por lo mismo, la exclusión de tales derechos a determinados individuos o grupos no estaría justificada, pues siendo una e igual la naturaleza que compartimos, serán también iguales las necesidades que le acompañen y los derechos de los que se nutra:

La naturaleza ha hecho a los hombres tan iguales en sus facultades de cuerpo y alma, que aunque puede encontrarse en ocasiones a hombres físicamente más fuertes o mentalmente más ágiles que otros, cuando consideramos todo junto, la diferencia entre hombre y hombre no es tan apreciable como para justificar el que un individuo reclame para sí cualquier beneficio que otro individuo no pueda reclamar con igual derecho (HOBBES, 1989, XIII, p. 105).

La filosofía política hobbesiana es, pues, una biopolítica que sienta las bases de un cosmopolitismo, anclado en el factum de que habitamos un mundo común. Y la afirmación de Améry, los límites de mi cuerpo son los límites de mi yo, nos hermanan y atañe universalmente a

${ }^{10}$ Como sabemos perfectamente, hay en el hombre pasiones insociables, que nos llevan al conflicto con los otros. Pero las pasiones que conducen a la insociabilidad pierden la batalla contra las pasiones que anhelan la paz y la seguridad, siendo en favor de éstas para quien la razón va a ponerse a trabajar y a encontrar los preceptos que nos han de conducir a aquélla. De aquí que escriba: "Y hasta aquí, lo que se refiere a la mala condición en la que está el hombre en su desnuda naturaleza, si bien tiene una posibilidad de salir de ese estado, posibilidad que, en parte, radica en sus pasiones, y, en parte, en su razón. Las pasiones que inclinan a los hombres a buscar la paz son el miedo a la muerte, el deseo de obtener las cosas para vivir cómodamente, y la esperanza de que, en su trabajo, puedan conseguirlas. Y la razón sugiere convenientes normas de paz, basándose en las cuales los hombres pueden llegar a un acuerdo". (HOBBES, 1989, XIII, p. 109).

${ }^{11}$ En este sentido, hay a nuestro entender un texto paradigmático en el que nos dice Hobbes: "La razón no es menos natural en el hombre que la pasión, y es la misma para todos los hombres, porque todos los hombres están de acuerdo en su voluntad de regirse y gobernarse de suerte que alcancen sus deseos, es decir, su propio bien, lo cual es obra de la razón". (HOBBES, 1979, XV, p. 210).

Revista Tópicos Educacionais, Pernambuco, v. 27, n. 02, p. 182-206, 2021. ISSN: 2448-0215.

https://periodicos.ufpe.br/revistas/topicoseducacionais/index

DOI: 10.51359/2448-0215.2021.251832 


\section{REVISTA TóPICOS EduCACIONAIS \\ Revista do Programa de Pós-Graduação em Educação \\ da Universidade Federal de Pernambuco (UFPE)}

todos por igual, más allá de particularismos y diferencias nacionales, culturales, étnicas o de la índole que sea. Nuestro cuerpo incorpora en sí mismo, y universalmente, un abanico de necesidades iguales. De aquí que afirmemos que somos ciudadanos del mundo, de un mismo mundo, el de nuestra corporeidad común, que nos hermana y crea lazos y exigencias comunes.

Y por ello, llamará Hobbes arrogantes a quienes pretenden excluir a otros de los derechos que naturalmente reclaman para sí, incurriendo en una fragante contradicción, pues estarían vulnerando una exigencia de la razón, una ley de naturaleza:

La desigualdad que ahora existe ha sido introducida por las leyes civiles. (...) Mas esto no sólo está reñido con la razón, sino con la experiencia. (...). En consecuencia, si la naturaleza ha hecho a los hombres iguales, dicha igualdad debe ser reconocida. Y por tanto, doy como novena ley de naturaleza la siguiente: que cada hombre reconozca a su prójimo como a su igual por naturaleza. El quebrantamiento de este precepto es el orgullo.

De esta ley depende otra: que al entrar en un estado de paz, ningún hombre exija para sí ningún derecho que de buena gana no acepte ver también reservado para todos los demás. Así como a todos los hombres que buscan la paz les es necesario renunciar a ciertos derechos naturales, es decir, que no tienen libertad de hacer todo lo que deseen, así también es necesario, para que un hombre conserve su vida, retener algunos otros: el derecho de gobernar su propio cuerpo; el de poder disfrutar del aire, del agua; el de moverse de un sitio a otro, y todas esas otras cosas sin las cuales un individuo no puede vivir, o no puede vivir bien. $\mathrm{Si}$, a la hora de establecer la paz, los hombres requieren para sí lo que no quisieran que se les concediese a otros, están infringiendo la ley precedente, que ordena reconocer una igualdad natural entre todos; y, por consiguiente, están yendo contra la ley de naturaleza. Quienes observan esta ley son aquellos a quienes llamamos modestos, y quienes la quebrantan reciben el nombre de arrogantes. A la violación de esta ley los griegos la llamaban pleonexía, es decir, desear más de lo que a uno le corresponde (HOBBES, 1989, XV, p. 129-130).

Al mismo tiempo, conviene tener presente que la autoconservación es, en un primer nivel, la primera exigencia racional de todo ser vivo, y, por tanto, también del ser humano. Pero decir que la vida es el summum bonum no sólo convierte al cuerpo en un límite infranqueable para los dictados del soberano, sino también, y ello queda patente en la hipotética situación previa a toda organización política de los individuos, en fuente de tensión y conflicto, pues cada cual querrá siempre preservar su vida a toda costa, y satisfacer sus deseos. De aquí que tantas veces los seres humanos se quejen por tener que ceder su derecho a disponer de todo; pero esta queja, en

Revista Tópicos Educacionais, Pernambuco, v. 27, n. 02, p. 182-206, 2021. ISSN: 2448-0215.

https://periodicos.ufpe.br/revistas/topicoseducacionais/index

DOI: 10.51359/2448-0215.2021.251832 


\section{REVISTA TóPICOS EduCACIONAIS \\ Revista do Programa de Pós-Graduação em Educação \\ da Universidade Federal de Pernambuco (UFPE)}

realidad, se alimenta de un profundo desconocimiento de lo que el hombre es, en cuanto a sus pasiones, y de lo que le tocaría vivir si no hiciera tal renuncia:

Alguno pudiera objetar que la condición de los súbditos es sobremanera miserable, puesto que están sometidos a los deseos y a otras pasiones irregulares de aquél o aquéllos que tienen en sus manos un poder tan ilimitado. Y, por lo común, quienes viven bajo un monarca piensan que es éste un defecto de la monarquía, y quienes viven bajo un régimen de democracia, o bajo cualquier otro tipo de asamblea soberana, atribuyen toda inconveniencia a esta forma de gobierno. Sin embargo, toda modalidad de poder, si está lo suficientemente perfeccionada como para proteger a los súbditos, es la misma. Y quienes se quejan no reparan en que el estado del hombre no puede nunca estar libre de incomodidades, y que aún la mayor que puede acaecer a la generalidad del pueblo bajo cualquier sistema de gobierno es insignificante si se la compara con las miserias y horrores que acompañan a toda guerra civil, o a esa disoluta condición en que se hallan los hombres cuando no hay autoridad ni sujeción a las leyes, y donde hay un poder coercitivo que les ate las manos y que no les permita caer en la rapiña ni en la venganza (HOBBES, 1989, XVIII, p. 153-154).

Mas, en Hobbes estamos lejos de incurrir en un pesimismo antropológico, pues, por otra parte, en el laberinto de las pasiones, la razón tratará siempre de abrirse paso hacia la paz. Éste es, sin duda, uno de los pilares esenciales de su esperanza, anclada siempre en la realidad y en la razón:

Y hasta aquí, lo que se refiere a la mala condición en la que está el hombre en su desnuda naturaleza, si bien tiene una posibilidad de salir de ese estado, posibilidad que, en parte, radica en sus sus pasiones, y, en parte, en su razón.

Las pasiones que inclinan a los hombres a buscar la paz son el miedo a la muerte, el deseo de obtener las cosas necesarias para vivir cómodamente, y la esperanza de que, con su trabajo, puedan conseguirlas. Y la razón sugiere convenientes normas de paz, basándose en las cuales los hombres pueden llegar a un acuerdo. Estas normas reciben el nombre de Leyes de Naturaleza, (...)”. (HOBBES, XIII, p. 109).

Tal sería, pues, la doble faz de una corporeidad que nos constituye y que nos lleva, de una parte, a levantar un dique frente a las amenazas del poder; pero, de otra, nos invita a satisfacer sus demandas ciegamente, afirmándonos en nuestra mera individualidad. Mas Hobbes nos advertirá de que por la vía del individualismo feroz, en el que los sujetos histérica y salvajemente pretenden garantizar su autoconservación, nos deslizaremos hacia una ilimitada pugna de pretensiones que

Revista Tópicos Educacionais, Pernambuco, v. 27, n. 02, p. 182-206, 2021. ISSN: 2448-0215. https://periodicos.ufpe.br/revistas/topicoseducacionais/index DOI: $10.51359 / 2448-0215.2021 .251832$ 


\section{REVISTA TóPICOS EduCACIONAIS \\ Revista do Programa de Pós-Graduação em Educação \\ da Universidade Federal de Pernambuco (UFPE)}

acabará, a buen seguro, en la conocida guerra de todos contra todos ${ }^{12}$. El caos, el desorden y la muerte serán los resultados directos de esta actitud ciega de quienes pretenderán a toda costa salvaguardar la vida por encima, si ello fuera necesario, de la de los otros. Pero una situación tal acabará siendo insostenible en la práctica: la inseguridad es permanente, y en estas condiciones no hay vida humana posible. De manera que si verdaderamente los individuos quieren protegerse tendrán que acudir a pactos, ceder su irreprimible derecho a disponer de todo en manos del soberano (HOBBES, 1989, XVII, p. 144s), y que tal soberano sea quien dicte lo justo y lo injusto, lo permitido y lo no permitido, así como que sea él quien ostente, legítimamente, la interpretación de la ley (HOBBES, 1989, XVIII, p. 151).

De este modo, y a simple vista, el soberano hace su entrada en el escenario político con un poder ilimitado. Pero que aquél carezca de límites en el plano político, pues de lo contrario no sería tal, no significa que no esté cercado por límites racionales en el ejercicio del mismo, pues de lo contrario este sería, a todas luces, irracional. En otras palabras: el soberano habrá de estar sujeto a las demandas de la racionalidad, o se precipitará por la pendiente del abuso, arbitrario e irracional, del poder ${ }^{13}$.

¿Quién pondrá en duda que en Hobbes asistimos a una obsesión por la paz? Como es bien sabido, tal empeño distaba mucho de ser azaroso, ubicándose en el contexto de su total rechazo de la sangrienta guerra civil inglesa. Y desde luego que la primera idea hobbesiana será la de que el soberano sólo puede ser uno, rememorando enseñanzas bíblicas, y que, por tanto, no cabe más

12 En efecto, insiste nuestro autor que, a diferencia de las abejas y las hormigas, "los hombres están compitiendo continuamente por el honor y la dignidad, cosa que no hacen estas criaturas. Como consecuencia, surge entre los hombres, por esa razón, envidia y odio, y, en última instancia, la guerra". (HOBBES, 1989, XVIII, p. 143).

${ }^{13}$ Como muy bien nos ha advertido el profesor Tierno Galván, en un breve pero excelente estudio, la filosofía política de Hobbes quiere, fundamentalmente, hacer frente al miedo político. Por ello, el Estado “(...) tiene que cuidar de sus súbditos, no producir en ellos un terror pánico que retrotraería las cosas al estado de naturaleza, es decir, al estado previo al acuerdo o pacto y a la guerra de todos contra todos". Y un poco más adelante, añade algo que nos parece esencial: "Críticos e historiadores han confundido la posesión absoluta del poder con el ejercicio absoluto del poder. En uno u otro contexto el valor de la expresión 'absoluto' cambia. En el primer caso posee connotaciones metafísicas, y quiere decir que no tiene superior en su orden; en el segundo posee connotaciones específicamente políticas y administrativas, y quiere decir que impide, arbitrariamente, la participación de los ciudadanos en la formación y aplicación de las leyes.” (TIERNO, 1991). El propio Hobbes deja bien claro que es partidario no de dividir el poder, pero sí de limitarlo en su ejercicio al ámbito moral de la ley natural (HOBBES, 1993, VII, p. 70).

Revista Tópicos Educacionais, Pernambuco, v. 27, n. 02, p. 182-206, 2021. ISSN: 2448-0215.

https://periodicos.ufpe.br/revistas/topicoseducacionais/index

DOI: 10.51359/2448-0215.2021.251832 


\section{REVISTA TóPICOS EDUCACIONAIS \\ Revista do Programa de Pós-Graduação em Educação \\ da Universidade Federal de Pernambuco (UFPE)}

obediencia que a un soberano (sea hombre o asamblea), o la disputa estará servida ${ }^{14}$. Sólo aquél, entonces, detentará todo el poder, si ha de preservarse la paz (HOBBES, 1989, XVIII).

Pero, como venimos diciendo, el carácter ilimitado del poder, en el sentido de no estar supeditado a otro poder, no significará que al soberano le esté todo permitido. ¿Es que ahora el Leviatán, ese dios mortal que ha de velar por los individuos, acabará convirtiéndose también él en un lobo para el hombre? Mas que eso pueda ocurrir en la práctica no se discute. Pero que tal conducta quepa legitimarse teóricamente en el seno del pensamiento hobbesiano es muy distinto. Y ello porque para Hobbes la política sólo es la alternativa racional a ese insufrible e hipotético estado de naturaleza, en el que los individuos se muestran incapaces de poner freno a sus pretensiones, y que no puede sino terminar degenerando en una interminable guerra de todos contra todos, donde efectivamente el hombre no puede ser ya sino un lobo para el hombre. Pero esto es precisamente lo que se pretende evitar cuando los individuos pactan entre sí, y ceden su irreprimible derecho a disponer de todo en manos de aquél. ¿Qué sentido tendría ahora otorgar a éste un poder tal que se convirtiera en una amenaza para el individuo? Y recordemos: "Salus populi suprema lex"15: "Todos los deberes de los gobernantes se encierran en este único: la ley suprema es la salvación del pueblo" (HOBBES, 1993, XIII, 113); o cuando en la introducción misma al Leviatán insiste en que la salus populi es la finalidad por la que tiene justificación, otorgando legitimidad al poder soberano:

La función del soberano, ya sea éste un monarca o una asamblea, consiste en el fin para el cual fue investido con el poder soberano, a saber, procurar la seguridad del pueblo, a lo cual está obligado por ley de naturaleza, así como a rendir cuenta de ello a Dios, que es el autor de dicha ley, y sólo a Él. Pero por seguridad no debe aquí entenderse una mera preservación, sino también todas las demás satisfacciones de la vida que cada hombre, mediante su legítimo trabajo, y sin peligro o daño para el Estado, adquiera para sí.

Y se supone que esta función debe ser llevada a cabo, no prestando cuidado a los individuos más allá de lo que se requiera para protegerlos de injurias cuando formulan una queja, sino más bien mediante una providencia general, contenida en la doctrina y en el ejemplo, y mediante la legislación y ejecución de leyes justas a las que los

\footnotetext{
${ }^{14}$ Se refiere Hobbes muy especialmente a la disputa entre el poder religioso y el poder terrenal (HOBBES, 1989, XXIX, $\mathrm{p}$. 262).

${ }^{15}$ Insistir en la importancia que para Hobbes tiene la salus populi nos parece esencial. Para no extendernos traeremos a colación sólo el siguiente texto: “¿Cuáles son esas leyes llamadas fundamentales? Pues no entiendo cómo una ley puede ser más fundamental que otra, con la sola excepción de la ley natural que nos obliga a todos a obedecer a aquél, quienquiera que fuere, a quien legítimamente y por nuestra propia seguridad hemos prometido obedecer; ni ninguna otra ley fundamental para un rey salvo la salus populi, la seguridad y bienestar de su pueblo". (HOBBES, 1992a, p. 88-89).

Revista Tópicos Educacionais, Pernambuco, v. 27, n. 02, p. 182-206, 2021. ISSN: 2448-0215.

https://periodicos.ufpe.br/revistas/topicoseducacionais/index
}

DOI: $10.51359 / 2448-0215.2021 .251832$ 


\section{REVISTA TóPICOS EduCaCiONAIS}

Revista do Programa de Pós-Graduação em Educação

da Universidade Federal de Pernambuco (UFPE)

individuos puedan recurrir en aquellos casos que los afecten (HOBBES, 1993, XXX, p. 267).

La idea es importante porque nos hace ver claramente cuál es el norte y guía de toda la concepción política hobbesiana. No podemos, pues, perder de vista este esencial detalle, a menos que queramos representarnos al soberano ejerciendo arbitrariamente su ilimitado poder en un vacío axiológico. Pero tal no es la concepción hobbesiana del poder, que tiene en esta salus populi un contenido fundamental y un límite racional a su ejercicio. Y, como venimos insistiendo, no podía ser de otro modo, pues precisamente el Estado surge como alternativa racional al caos y a la vulnerabilidad a la que quedan expuestos los individuos, cuando no hay ningún poder político que los proteja.

De manera que no es la mera seguridad, o la mera defensa de los individuos, frente a la supuesta amenaza que pueden constituir las pretensiones de los otros, lo que únicamente preocupa a Hobbes. Esta salus populi, este bienestar del pueblo que, recordémoslo, ha de ser norte y guía de la política, reclama del poder un cuidado: políticas, en suma, que velen por el bienestar de aquéllos. Por ello, no se trata sólo de concebir al Estado como una suerte de coraza, judicial y policial, para proteger al ciudadano de amenazas externas, como si se tratara de un Estado mínimo al modo de Nozick. Hobbes lo concibe como un Estado racional que ha de poner en marcha políticas activas, orientadas a crear las condiciones de posibilidad para que la vida de aquéllos encuentre abonado el terreno en sus plurales proyectos de vida buena, y donde igualmente se optimicen todos los recursos:

Por salvación debe entenderse no sólo la conservación de la vida de cualquier forma, sino, en la medida de lo posible, de la vida feliz. Porque esa fue la razón por la que los hombres se agruparon voluntariamente en Estados instituidos, para poder vivir lo más felices posible en la medida en que lo permite la condición humana. En consecuencia, los que han aceptado la administración del poder supremo en esa clase de Estados, obrarían contra la ley natural (al obrar contra la confianza depositada en ellos por los que les encargaron la administración del poder), si no se esforzasen todo lo que las leyes le permitan en que los ciudadanos estén provistos abundantemente de todos los bienes necesarios no sólo para la vida, sino para una vida placentera (HOBBES, 1993, XIII, p. 113).

Revista Tópicos Educacionais, Pernambuco, v. 27, n. 02, p. 182-206, 2021. ISSN: 2448-0215.

https://periodicos.ufpe.br/revistas/topicoseducacionais/index

DOI: $10.51359 / 2448-0215.2021 .251832$ 


\section{REVISTA TóPICOS EduCaCiONAIS \\ Revista do Programa de Pós-Graduação em Educação da Universidade Federal de Pernambuco (UFPE)}

En efecto, tras este tipo de declaraciones entendemos que no sólo el terror pánico es lo que se pretende evitar con la figura del soberano; un terror que deviene insufrible en el salvaje estado de naturaleza, donde no hay ley, ni orden alguno, y donde campea a sus anchas la arbitraria voluntad de los individuos. Mas el Estado se legitima por su fin fundamental: preservar la paz y proveer, abundantemente, de todos los bienes necesarios, no sólo para la vida, sino para poder alcanzar una vida placentera, feliz, hasta donde lo permita la humana condición. La legitimidad del soberano empieza y termina, pues, ahí: velar por nuestra seguridad, y promover políticas que creen las condiciones de posibilidad de una vida digna, donde no sólo se atienda a la satisfacción de las necesidades más perentorias, sino donde se contemple también el desarrollo de aquellos otros aspectos que, entrando igualmente en el capítulo de las necesidades, convierten nuestra vida en algo digno de ser vivido, pues, de este modo, se habrán sentado las bases a partir de las cuales los hombres podrán aspirar a impulsar sus particulares proyectos de vida, haciendo de ésta algo más que un asunto de mera supervivencia. Por tanto, alcanzar una vida segura, digna, y hasta placentera será un desafío no solo para los individuos sino para el Estado, preocupado no sólo de la autoconservación de aquéllos, sino de su bienestar (salus populi).

Mas, en este respecto, no han faltado voces que, como la de Kant, han acusado a Hobbes de paternalismo $^{16}$. El propio Hegel atribuyó al Estado hobbesiano el calificativo de despótico (HEGEL, 1977, p. 334). Pero ni paternalismo, ni despotismo nos parecen juicios adecuados. Porque, en ningún caso es suprimida la libertad de los individuos para articular sus particulares

\footnotetext{
${ }^{16}$ Un texto ejemplar de Kant nos parece al respecto el siguiente, cuando al hablar del concepto de derecho dice que “(...) procede enteramente del concepto de libertad en las relaciones externas de los hombres entre sí, y no tiene nada que ver con el fin que todos los hombres persiguen de modo natural (el propósito de ser felices) ni con la prescripción de los medios para lograrlo; de suerte que, por tanto, este fin no ha de inmiscuirse de ninguna manera en aquella ley a título de fundamento para determinarlo". (KANT, 1986, p. 26) Kant (p. 27) contrapone, así, libertad y felicidad, porque "nadie me puede obligar a ser feliz a su modo'. Mas a esto hay que añadir lo llamativo que resulta el hecho de que el propio Kant comente la sentencia de Hobbes: salus populi suprema civitatis lex, pero insistiendo en que esta salus populi depende sólo de la garantía de libertad, porque la felicidad no es universalizable y, por tanto, no cabe desarrollarla ni plasmarla tampoco en el plano jurídico. (KANT, 1986 p. 38). En este sentido, nos sorprende que Kant no haya distinguido el contenido de la felicidad de las condiciones que la hacen posible, siendo esto de lo que verdaderamente se ocupó Hobbes. Paternalismo, sería entonces decirle al ciudadano de qué modo tiene que ser feliz. Pero Hobbes sabía perfectamente de la pluralidad de concepciones de la felicidad y, por tanto, de la diversidad de modos de definir qué sea una vida buena. Y, sin embargo, consideraba que había unos mínimos sin los cuales no es posible poner en marcha ningún proyecto propio de felicidad. Estos mínimos pasan por el reconocimiento del orden y paz social, seguridad, y fomento de políticas que mejoren las condiciones materiales de los ciudadanos -salus populi-, pues de no darse toda la libertad de la que presume Kant, ésta no sería más que un mero deseo, carente de toda concreción en el mundo, donde nos las habemos realmente con dificultades sin cuento, y en el que, después de todo, transcurre nuestra vida.

Revista Tópicos Educacionais, Pernambuco, v. 27, n. 02, p. 182-206, 2021. ISSN: 2448-0215.

https://periodicos.ufpe.br/revistas/topicoseducacionais/index

DOI: $10.51359 / 2448-0215.2021 .251832$
} 


\section{REVISTA TóPICOS EDUCACIONAIS \\ Revista do Programa de Pós-Graduação em Educação \\ da Universidade Federal de Pernambuco (UFPE)}

concepciones de qué sea una vida buena. Tan sólo es limitado el libre derecho adisponer de todo; derecho, dicho sea de paso, más propio de individuos que viven en un medio salvaje, que de aquellos que aspiran a vivir organizados racionalmente en una comunidad política, donde el respeto, y por tanto, la sujeción a una ley pública común como medida de lo justo y de lo injusto, es la primera de todas las exigencias (HOBBES, 1989, XXVI) ${ }^{17}$.

Ahora bien, tampoco podemos perder de vista que para Hobbes la ley positiva no opera en un vacío axiológico-racional. Junto a ley positiva, jurídica y políticamente eficaz, hay que considerar a la ley natura ${ }^{18}$, que también juega un importante papel en su sistema. Esta ley natural no es más que el conjunto de dictados de la razón ${ }^{19}$, o conclusiones racionales a las que nuestra razón llega cuando el motivo fundamental de su actividad teórica no es sino la inteligente conservación del individuo. Dicho con otras palabras: si preguntamos a la razón qué hay que hacer para lograr la paz y salvaguardar nuestra integridad, aquélla responderá con una serie de mandatos que, dice Hobbes, hemos llamado impropiamente ley natural (HOBBES, 1989, XIII, p. 109), pero que no son sino conclusiones de la razón en orden a velar por la $\mathrm{paz}^{20}$. Estos dictados de la razón, que Hobbes enumera y explica detenida y detalladamente en el Leviatán, acaban por resumirse en un principio fundamental, a saber, la regla de oro de la moral: no hagas a otro lo que

\footnotetext{
${ }^{17}$ Antes nos había dicho: "De esta ley de naturaleza que nos obliga a transferir esos derechos que, de ser retenidos, impiden la paz de la humanidad, se deriva una tercera ley, que es ésta: que los hombres deben cumplir los convenios que han hecho. Sin esta ley, los convenios se hacen en vano y sólo son palabras vacías; y como de ese modo permanece el derecho de todos los hombres a todas las cosas, nos encontramos aún en un estado de guerra.

Y en esta ley de naturaleza consiste la fuente y el origen de la JUSTICIA. Porque donde no ha tenido lugar un convenio, no se ha transferido ningún derecho a todo; $y$, en consecuencia, ninguna acción puede ser injusta. Pero cuando un convenio ha sido hecho, entonces es injusto quebrantarlo. Y la definición de INJUSTICIA no es otra que el incumplimiento de un convenio. Y todo aquello que no es injusto es justo". (HOBBES, 1989, XV, p., 121).

${ }^{18}$ Son muchos los lugares en los que Hobbes nos habla de las leyes naturales (HOBBES, 1989, XIV-XV). De especial importancia nos es el siguiente texto, en el que vemos como dichas leyes naturales se ubican en el ámbito de la ética: "Por lo tanto, mientras el hombre está en su condición natural, que es un estado de guerra, su apetito personal es la medida de lo bueno y de lo malo. Y por eso todos los hombres han venido a acordar esto: que la paz es lo bueno, y que también son buenos los medios o caminos que conducen a ella, que son, como he mostrado antes, la justicia, la gratitud, la modestia, la equidad, la misericordia, y el resto de las leyes de naturaleza, esto es, las virtudes morales". (HOBBES, 1989, XV, p. 133). Sobre esta cuestión puede verse una buena síntesis de las interpretaciones más destacadas en Badillo (1998, cap. 4), así como en Saravia (2011), destacando la importancia de Hobbes para el liberalismo, como ya subrayara Strauss. Para la aportación de Hobbes al pensamiento liberal De Julios, (1997, 2000).

19 "Los hombres han solido dar el nombre de leyes a estos dictados de la razón, pero lo han hecho impropiamente." (HOBBES, 1989, XV, p. 133).

${ }^{20}$ En efecto, nos dice: "Y la razón sugiere convenientes normas de paz basándose en las cuales los hombres pueden llegar a un acuerdo." (HOBBES, 1989, XIII, p. 109). Pero, llegar a un acuerdo no significa anular la pluralidad, sino reconocerla. En este sentido, merece destacar la opinión de J. M. ${ }^{a}$ Rosales, para quien en Hobbes, la unidad de la soberanía no anula su tesis básica de la constitución plural del poder (ROSALES, 1998, p. 54s)..

Revista Tópicos Educacionais, Pernambuco, v. 27, n. 02, p. 182-206, 2021. ISSN: 2448-0215.

https://periodicos.ufpe.br/revistas/topicoseducacionais/index

DOI: $10.51359 / 2448-0215.2021 .251832$
} 


\section{REVISTA TóPICOS EDUCACIONAIS \\ Revista do Programa de Pós-Graduação em Educação \\ da Universidade Federal de Pernambuco (UFPE)}

no quisieras que te hicieran a $\mathrm{ti}^{21}$. Pues bien, lo que en este momento no deberíamos olvidar es que para Hobbes la ley positiva, dictada por el soberano, ha de desplegarse en el seno de la ley natural, lo que significa que el soberano, en el ejercicio del poder, tampoco puede dejar atrás a la razón y sus demandas; o, lo que es lo mismo: que el poder ha de estar sujeto a la racionalidad y, por tanto, a la ley natural, en ese listado de prescripciones que Hobbes nos presenta (HOBBES, 1989, XIV$\mathrm{XV}$ ), si aquél no quiere ser un poder irracional e ilegítimo ${ }^{22}$. Políticamente, pues, el soberano es tal, y lo es absolutamente, porque no hayninguna instancia superior que lo limite; pero moralmente, el soberano está cercado por un límite: la aspiración a ejercer una política racional. Y esta condición le exige ponerse en la piel del gobernado, pues en esto acaban resumiéndose, a fin de cuentas, el conjunto de prescripciones que la razón dicta a través de su desarrollo en la hobbesiana ley natural.

Sólo ahora estamos en condiciones de reconocer la importancia de la salus populi como exigencia fundamental del ejercicio del poder, y también fuente de su legitimidad. Por ello, los límites que impone la racionalidad al ejercicio de aquel son: la preservación de la vida, el respeto a la integridad personal, y la exigencia de una política que ponga en marcha actuaciones orientadas al logro de una vida digna y placentera. ¿Pero cabe, entonces, hablar aquí de paternalismo? Porque paternalista sería que el Estado entrara a definir el concepto de felicidad para los individuos, mientras que el modelo hobbesiano lo único que hace es delimitar lo bueno de lo malo, pero en el sentido de lo justo respecto de lo injusto. Mas entrar en consideraciones acerca de cómo ser feliz es algo que Hobbes no contempla, precisamente porque parte de una concepción plural acerca de la felicidad, habida cuenta de que no existe ni lo que tradicionalmente se llamó finis ultimus, ni summum

${ }^{21}$ Como el mismo Hobbes reconoce, conocemos nuestro deber moral -pues la ley natural, o los dictados de la razón son expresión de la moralidad según él la entiende- con sólo ponernos en el pellejo ajeno, algo para lo cual no es necesario una inteligencia cultivada, pues “(...) nada es más fácil de conocer, incluso para el rudo sin letras, que la ley natural; mediante esta sola regla: que cuando dude de si lo que va a hacer a otro está de acuerdo con el derecho natural o no, se ponga en su lugar. En ese mismo instante, aquellas perturbaciones que le instigaban a hacerlo, como si hubiesen pasado al otro platillo de la balanza, le disuadirán de lo mismo. Y esta regla no sólo es fácil sino que ya desde antiguo se viene celebrando con estas palabras: no hagas a otro lo que no quieres que te hagan a ti”. (HOBBES, 1993, III, p. 40; 1989, XV, p. 131s). En este sentido, el gobernante, si quiere ser racional no tendrá otra opción que ponerse realmente en la piel del gobernado.

${ }^{22}$ Se refiere Hobbes a la equidad, la justicia, la gratitud y demás virtudes morales que favorecen la paz y que delimitan los contornos de la racionalidad tanto individual como política del soberano. Por ello insistirá Hobbes en el hecho de que como no obligan más que in foro interno queden recogidas en los desarrollos legales. "La ley natural y la ley civil están contenidas la una en la otra, y tienen igual extensión", nos dice, precisamente para insistir en la importancia de que la ley positiva se desarrolle dentro del marco de racionalidad que representa le lex naturalis, a la que no en vano llamará en otros lugares virtudes morales, teoremas o mandatos de la razón. (HOBBES, 1989, XXVI, p. 217).

Revista Tópicos Educacionais, Pernambuco, v. 27, n. 02, p. 182-206, 2021. ISSN: 2448-0215.

https://periodicos.ufpe.br/revistas/topicoseducacionais/index

DOI: 10.51359/2448-0215.2021.251832 


\section{REVISTA TóPICOS EDUCACIONAIS \\ Revista do Programa de Pós-Graduação em Educação \\ da Universidade Federal de Pernambuco (UFPE)}

bonum para el hombre ${ }^{23}$. En efecto, Hobbes reconocerá la imposibilidad de definir la felicidad en términos unívocos y universales. Y, sin embargo, pero precisamente por ello, preocuparse por la felicidad de los súbditos consistirá no en definir, paternalistamente, sus contenidos, sino en que el Estado vele por su seguridad; pero, a la par, en que trabaje para crear las condiciones materiales que hagan posible el máximum posible de bienestar para aquéllos. Y tal es la preocupación y celo por el bienestar de los gobernados, como razón de ser, junto a la seguridad, de toda su concepción de lo político, que afirmará sin ambages que no habrá jamás un soberano fuerte si estamos ante ciudadanos débiles (HOBBES, 1989, XXX, p. 276).

\section{Razones para la desobediencia al poder.}

Pero hay más razones que avalan esta interpretación que proponemos, pues cabría preguntarse si un soberano hobbesiano despótico, como lo supone Hegel, no nos retrotraería más bien, y, paradójicamente, a la inseguridad -pérdida de la confianza, de la que hablaba Améry-de la

23 "A lo que estoy refiriéndome es a esas cualidades de la humanidad, que tienen que ver con la pacífica convivencia y la unidad entre los hombres. Con este fin, debemos considerar que la felicidad en esta vida no consiste en el reposo de una mente completamente satisfecha. No existe tal cosa como ese finis ultimus, o ese summum bonum de que se nos habla en los viejos libros de filosofía moral. Un hombre cuyos deseos han sido colmados y cuyos sentidos e imaginación han quedado estáticos, no puede vivir. La felicidad es un continuo progreso en el deseo; un continuo pasar de un objeto a otro. Conseguir una cosa es solo un medio para lograr la siguiente. La razón de esto es que el objeto del deseo de un hombre no es gozar una vez solamente, y por un instante, sino asegurar para siempre el camino de sus deseos futuros. Por lo tanto, las acciones voluntarias y las inclinaciones de todos los hombres no solamente tienden a procurar una vida feliz, sino a asegurarla. Sólo difieren unos de otros en los modos de hacerlo. Estas diferencias provienen, en parte, de la diversidad de pasiones que tienen lugar entre hombres diversos, $\mathrm{y}$, en parte, de las diferencias de conocimiento y opinión que cada uno tiene en lo que respecta a las causas que producen el efecto deseado.

De manera que doy como primera inclinación natural de toda la humanidad un perpetuo e incansable deseo de conseguir poder tras poder, que sólo cesa con la muerte". (HOBBES, 1989, XI, p. 86-87). Y en otro lugar también leemos a propósito de la felicidad: "El éxito continuo en el logro de las cosas que un hombre desea de cuando en cuando, es decir, la continua prosperidad, es lo que los hombres llaman FELICIDAD; felicidad en esta vida, quiero decir. Porque mientras vivamos aquí no habrá tal cosa como una perpetua tranquilidad de ánimo, ya que la vida misma es movimiento, y jamás podemos estar libres ni de deseo ni de miedo, lo mismo que tampoco podemos estar libres del sentido. El tipo de felicidad que Dios ha dispuesto para quienes le honran con devoción, será algo que un hombre disfrutará desde el momento en que lo conozca. Pero estos son goces que ahora nos resultan incomprensibles, como ininteligible nos resulta también el término visión beatífica que usan los escolásticos". (HOBBES, 1989, VI, p. 58). Pero precisamente porque los hombres carecen de un concepto unánime de felicidad, y muestran un deseo permanente de satisfacerla, entran en rivalidades de espada y de pluma, algo muy distinto de lo que sucede con otro tipo de disputas, como las geométricas, en las que no hay ambiciones en juego, pues, de ser así, nadie nos libraría de confrontaciones en tal respecto. La maestría en el uso de la ironía alcanza en este texto de Hobbes una altura difícilmente superable. (HOBBES, 1989, XI, p. 90-91).

Revista Tópicos Educacionais, Pernambuco, v. 27, n. 02, p. 182-206, 2021. ISSN: 2448-0215.

https://periodicos.ufpe.br/revistas/topicoseducacionais/index

DOI: 10.51359/2448-0215.2021.251832 


\section{REVISTA TóPICOS EDUCACIONAIS \\ Revista do Programa de Pós-Graduação em Educação da Universidade Federal de Pernambuco (UFPE)}

que el pacto pretendió sacarnos. Mas para despejar como infundada la hegeliana sospecha tal vez sea lo mejor indagar las razones que Hobbes esgrimió en favor de la desobediencia.

Al principio de nuestra exposición hablábamos de la vida como el summum bonum, y de que ese cuerpo que somos, con todas sus demandas, es el destinatario del ejercicio del poder. Ahora parece claro: ya no nos extraña que Hobbes considere al bienestar del pueblo (salus populi) como suprema lex, y, por tanto, horizonte de justificación de lo político. Fuera de ella, lo político se deslegitima, pierde todo su sentido. Y esto, a su vez, nos permite comprender, complementariamente, que haya al menos dos situaciones en las que la supuesta obediencia debida al soberano se resquebrajaría: por una parte, si nuestra seguridad, en el más amplio sentido del término, se pone en peligro (por circunstancias externas, cabría apuntar, o incluso por actuaciones del soberano); por otra, y, desde luego, no menos importante, si nuestra integridad personal (y hablamos una vez más de nuestra vida y de nuestro cuerpo) corriera el más mínimo riesgo. Pero veamos estas doscircunstancias más despacio.

Si leemos en el Leviatán el capítulo XXI, o su Repaso y conclusión, encontramos allí dos ideas que sintetizan muy bien el punto de vista de Hobbes de hasta dónde llega la obediencia al soberano. En primer lugar, se cura en salud, saliendo al paso de una posible objeción: ¿qué pasaría en tiempos de guerra con este asunto? Su respuesta es clara, y sin embargo, está sujeta, con mucho tacto político, a una interesante y polémica condición. Hobbes se inclina por la lealtad al soberano, que en tiempos de paz ha velado por la conservación de nuestro cuerpo y de nuestra vida, favoreciendo incluso las circunstancias que nos permitan aspirar a una vida placentera, como ya se ha visto. En efecto, en su Repaso y conclusiones, afirma:

A las Leyes de Naturaleza, expuestas en el capítulo XV, añado ahora ésta: que todo hombre está obligado por naturaleza, hasta donde le sea posible, a proteger a la autoridad en tiempo de guerra, pues es esa autoridad quien lo protege a él en tiempo de paz. Porque quien reclama tener el derecho natural de preservar su propio cuerpo, no puede reclamar por derecho natural la destrucción de aquél por cuya fuerza se ve protegido; de hacerlo estaría contradiciéndose a sí mismo (HOBBES, 1989, p. 540).

Como puede apreciarse, Hobbes nos está planteando aquí la obligación de una reciprocidad con respecto a la protección que, en tiempos de paz, recibimos del soberano. Y, sin embargo, ha 


\section{REVISTA TóPICOS EduCaCiONAIS \\ Revista do Programa de Pós-Graduação em Educação \\ da Universidade Federal de Pernambuco (UFPE)}

puntualizado: hasta donde le sea posible. Esta observación no es un añadido fortuito, y menos en quien otorga tanta importancia a la exactitud y rigor expresivos, sino que preludia otra idea fundamental, que resumirá del siguiente modo:

Y así, doy fin a mi Discurso sobre el Gobierno Civil y el Eclesiástico, ocasionado por los desórdenes de la hora presente. Lo he escrito sin parcialidad, sin un propósito de interés particular y sin más intención que la de poner a la vista de los hombres la mutua relación que existe entre la protección y la obediencia, cuya inviolable observación es requerida por la condición natural del hombre y por las leyes naturales y positivas (HOBBES, 1989, p. 547).

Sin lugar a dudas, en el esquema hobbesiano, la obediencia al poder resulta en buena medida de nuestra finita y humana condición, expuesta permanentemente a los riesgos de las contingencias externas; siempre, claro está, que queramos preservar la vida y desarrollarla, porque aquélla, desligada de todo compromiso político, y ubicada en la mera naturaleza, se vería fatalmente arrastrada, a consecuencia de lo insaciable del deseo, a una insostenible situación de permanentes e insufribles conflictos. En este sentido, tal obediencia es un requerimiento, conclusión o mandato de la razón ${ }^{24}$, siendo la única salida razonable a nuestra pretensión, inteligente, de supervivencia, situándonos en un ámbito no de mera naturaleza, sino de moralidad. Subimos, pues, y por así decirlo, un peldaño: de los irrefrenables deseos, a las conclusiones que la razón nos dicta para salvaguardar la paz (leyes naturales). Pero si el peldaño de las inclinaciones nos conduce al de las prescripciones de la razón, en orden a preservar la paz, aún la mera moralidad no será suficiente para lograr semejante objetivo. Por ello, hemos de subir un escalón más, y he aquí que no nos quede más remedio que ubicarnos ya en el horizonte de lo político, un espacio en el que, sin embargo, no podremos dejar atrás, en ningún momento, el marco de racionalidad (moralidad) que representan las leyes de naturaleza. Por ello, a nuestro entender la idea fundamental es: ni la mera naturaleza, ni la moral por sí mismas son aliados suficientes para garantizar la paz. Necesitamos un vínculo de mayor consistencia y viabilidad práctica, y aquí es

${ }^{24}$ Se refiere Hobbes a la leyes naturales en los siguientes términos: "Otra división de las leyes es la que establece una distinción entre naturales y positivas. Naturales son aquellas leyes que lo han sido desde toda la eternidad. No solamente reciben el nombre de leyes naturales, sino también el de leyes morales, pues consisten en las virtudes morales como la justicia, la equidad, y todos los demás hábitos mentalesque conducen a la paz y a la caridad, de los cuales ya he hablado en los capítulos 14 y 15”. (HOBBES, 1989, XXI, p. 229).

Revista Tópicos Educacionais, Pernambuco, v. 27, n. 02, p. 182-206, 2021. ISSN: 2448-0215.

https://periodicos.ufpe.br/revistas/topicoseducacionais/index

DOI: $10.51359 / 2448-0215.2021 .251832$ 


\section{REVISTA TóPICOS EDUCACIONAIS \\ Revista do Programa de Pós-Graduação em Educação \\ da Universidade Federal de Pernambuco (UFPE)}

donde entrará en escena lo político como garantía y sustento de aquélla. Ahora bien, esto nos exigirá obediencia al poder, si es que no queremos desintegrar ese espacio común, que es en el único en el que podremos estar realmente a salvo; y el único en el que cabrá desarrollar todas nuestras personales aspiraciones, satisfaciendo nuestras particulares concepciones de qué sea una vida buena.

Mas en lo que ahora queremos insistir es que esta obediencia, que es inviolable, está sometida, y por estricta coherencia interna, a una ineludible condición: la obediencia debida llegará hasta donde alcance la protección ${ }^{25}$. Porque allí donde el súbdito no está ya protegido por el soberano, el deber de obediencia decae. En otras palabras, obediencia y protección van de la mano, hasta el extremo de que, cabría añadir aquí, si el soberano pone en peligro mi seguridad, entonces ya no me debo a aquél. Alcanzada esta conclusión, cabe hacerse la pregunta esencial: si tan inexcusable es la exigencia de protección, hasta el punto de ser la condición a la que se limita o somete al mismísimo deber de obediencia, pilar y fundamento del Estado, ¿cómo entonces iba a permitir Hobbes un trato despótico contra el ciudadano? Ni la salus populi, ni esta protección debida, en justa proporcionalidad a la obediencia debida, lo autorizan. Y tanto es así que J. Habermas ha visto en el planteamiento hobbesiano el origen del pensamiento liberal, en lo que a protección del individuo concierne, y ello, sobre todo, porque en su facticidad el poder tiene que estar limitado racionalmente por la ley natural (HABERMAS, 1987, p. 72-73). En efecto, los principios morales, ese segundo peldaño al que nos venimos refiriendo, duran poco en el escenario de las interacciones individuales, sin un poder político que los desarrolle y tutele. Pero a su vez, un poder político que estuviera al margen de esta moral racional y, por tanto, universal, basada en el respeto a la vida, la integridad personal y el derecho de todos a una vida digna y placentera; un poder, en definitiva, que no tuviera estas condiciones bien en cuenta sería, sin lugar a dudas, una fortaleza que estaría labrando su propia ruina (HOBBES, 1993, X, p. 90), al tiempo que perdería todo sentido y legitimidad para Hobbes ${ }^{26}$.

${ }^{25}$ Esta idea la encontramos muy bien expuesta en El ciudadano, cuando escribe: "Pues la seguridad es la razón de que los hombres se sometan a otros, y si ésta no se da, nadie entiende haberse sometido a otros ni haber perdido el derecho a todo sin que se haya provisto a su seguridad.” (HOBBES, 1993, VI, p. 57).

${ }^{26}$ Y como muy bien nos recordó F. Tönnies (1988, p. 270), también el soberano puede ser digno de ser tratado hostilmente si no cumple con la ley natural. Y es que el propio Hobbes justifica matar al que gobierna hostilmente, y, por tanto, sin Revista Tópicos Educacionais, Pernambuco, v. 27, n. 02, p. 182-206, 2021. ISSN: 2448-0215.

https://periodicos.ufpe.br/revistas/topicoseducacionais/index DOI: $10.51359 / 2448-0215.2021 .251832$ 


\section{REVISTA TóPICOS EduCACIONAIS \\ Revista do Programa de Pós-Graduação em Educação da Universidade Federal de Pernambuco (UFPE)}

Pero la cautela de nuestro autor, entendida como un someter a cierto control - desde una instancia exclusivamente racional, por supuesto- al poder mismo, la vemos perfectamente ejemplificada en otra situación excepcional, en la que se deja abierta la puerta para la desobediencia: nos referimos a la circunstancia de que el cuerpo, en tanto que sede de ese summum bonum que es la vida, sea el destinatario de un posible y real daño, o incluso de la muerte. Entonces, apuntará Hobbes, decaerá el supuesto deber de obediencia debida, pues el derecho de autoconservación estará aquí también por encima incluso del deber de someternos al soberano. En efecto, en el capítulo XXI del Leviatán, que lleva precisamente por título, De la libertad de los súbditos, leemos:

Ya he mostrado antes, en el capítulo 14, que aquellos convenios en los que un hombre renuncia a la defensa de su propio cuerpo son inválidos. Por consiguiente, si el soberano manda a un hombre (aunque este haya sido condenado justamente) que se mate, se hiera o se mutile a sí mismo, o que no haga resistencia a quienes lo asaltan, o que se abstenga de hacer uso de comida, aire, medicina y cualquier otra cosa sin la cual no podrá vivir, ese hombre tendrá la libertad de desobedecer (HOBBES, 1989, XXI, p. 179).

En buena lógica con lo que venimos diciendo, hay que añadir que tampoco cabe forzar, por parte del soberano, la confesión de una culpa (HOBBES, 1989, XXI, p. 179), por lo que, en consecuencia, nuestro autor está privando de toda legitimidad posible a la tortura como procedimiento inculpatorio:

Un convenio que implique un acusarse a sí mismo sin garantía de perdón, es igualmente inválido. Porque en el estado natural, donde cada hombre es juez, no hay lugar para la acusación; y en el estado civil, la acusación es seguida por el castigo, el cual, al ser ejecutado por la fuerza, no obliga a ningún hombre a resistirse a padecerlo. Lo mismo puede decirse de la acusación contra aquellas personas cuya condena hace que un hombre caiga en un estado de miseria, como la acusación contra su padre, su esposa o su benefactor. Porque el testimonio de un acusador así, si no es dado voluntariamente, debe suponerse que está corrompido por naturaleza, y no debe aceptarse; y no puede obligarse a ningún hombre a testimoniar sabiendo que no puede darse crédito a su testimonio. De igual manera, las acusaciones que se obtienen mediante tortura no deben considerarse como testimonios. Porque el tormento sólo puede usarse como medio para alcanzar alguna conjetura, alguna luz en la posterior investigación y búsqueda de la verdad. Y lo que se confiesa en una situación así, tiende sólo a aliviar a quien está siendo torturado, y no a informar a los torturadores.

derecho, lo cual significa matar no a un soberano, ni a un tirano, sino a un declarado enemigo, por lo que habría que hablar más bien de hosticidio (HOBBES, 1993, XII, p. 105).

Revista Tópicos Educacionais, Pernambuco, v. 27, n. 02, p. 182-206, 2021. ISSN: 2448-0215.

https://periodicos.ufpe.br/revistas/topicoseducacionais/index

DOI: $10.51359 / 2448-0215.2021 .251832$ 


\section{REVISTA TóPICOS EduCaCiONAIS}

\section{Revista do Programa de Pós-Graduação em Educação}

da Universidade Federal de Pernambuco (UFPE)

Por tanto, esas confesiones no tienen suficiente valor de testimonio; pues quien se libera a sí mismo mediante una acusación, ya sea ésta verdadera o falsa, lo hace usando de su derecho de conservar la vida (HOBBES, 1989, XV, p 118-119).

Por otra parte, y siguiendo el rastro a los límites de la obediencia, el soberano podrá decidir matarme, pero no puede obligarme a matarme a mí mismo o a matar a nadie. En este punto, también tengo el derecho de oponer, como legítima, mi desobediencia. Y ello, porque cuando prestamos sumisión al soberano no lo hicimos para colocarnos en una situación de riesgo, sino todo lo contrario. Lo que ocurre es que esta circunstancia provocará un conflicto de legitimaciones de distinto orden, individualy estatal, pero ambas en sus pretensiones estarían al mismo nivel, pues Hobbes no pide la renuncia o abandono de ninguna de las dos partes en litigio, siendo, por ello, un conflicto difícilmente salvable. En efecto, por una parte, tendríamos al soldado, a quien se le ordena luchar contra el enemigo, pero que estaría en su pleno derecho de no matarlo. En tal caso no cometería injusticia, pues nadie puede obligarnos a matar a nadie, tal como acabamos de ver. Sin embargo, y por otra parte, en aras de la autoconservación del Estado, el soberano estaría también legitimado a perseguir y dar muerte a este soldado que se niega a matar al enemigo. La libertad y legitimidad para desobedecer la orden de batir al contrario es compatible, piensa nuestro autor, con el derecho del soberano a castigar esta actitud, en un ejercicio de legítima defensa, hasta con su muerte:

Ningún hombre está obligado por las palabras mismas a matarse ni a matar a ningún otro hombre; (...) Según esto, un hombre al que, en su condición de soldado, se le ordena luchar contra el enemigo, podrá en muchos casos, sin cometer injusticia, negarse a obedecer esa orden, si bien el soberano tendrá el derecho de castigar su negativa con la muerte; un caso así sería el del soldado que pone a un sustituto suficiente en su lugar; pues al actuar de este modo no estaría desertando de sus obligaciones para con el Estado. Y debe también hacerse alguna concesión a la timidez natural, no sólo de las mujeres, de las que no debe esperarse un servicio tan peligroso, sino también de los hombres cuyo coraje es feminoide. Siempre que los ejércitosluchan, tienen lugar huidas en uno de los bandos, o en los dos; sin embargo, cuando huir no es un acto de traición, sino simplemente de miedo, no se estima injusto que los hombres huyan, sino deshonrable. Por la misma razón, evitar la batalla no es injusticia, sino cobardía. Pero quien voluntariamente se enlista como soldado o está en calidad de mercenario, carece de la excusa de ser un temperamento timorato, y está obligado no sólo a ir a la batalla, sino también a no huir de ella sin el permiso de su capitán. Y cuando la defensa del Estado requiere en un momento que todos los que sean hábiles tomen las armas, todos están obligados a hacerlo; de no ser así, la

Revista Tópicos Educacionais, Pernambuco, v. 27, n. 02, p. 182-206, 2021. ISSN: 2448-0215.

https://periodicos.ufpe.br/revistas/topicoseducacionais/index

DOI: $10.51359 / 2448-0215.2021 .251832$ 


\section{REVISTA TóPICOS EDUCACIONAIS}

Revista do Programa de Pós-Graduação em Educação

da Universidade Federal de Pernambuco (UFPE)

institución de un Estado que los súbditos no tienen el propósito o coraje de preservar, sería vana (HOBBES, 1989, XX1, p. 179-180).

Por tanto, siempre cabría la posibilidad de intentar esquivar el castigo ${ }^{27}$, yprocurar que el soberano no supiera de nuestra negativa, con lo cual evitaríamos que en la práctica tal conflicto llegara a producirse. Resulta innecesario decir que con actitudes de este tipo, como la ahora sugerida por Hobbes, muchas de las atrocidades que han tenido y tienen a la guerra como telón de fondo, así como la búsqueda de pretextos y legitimaciones para la misma, encontrarían, en no pocas ocasiones, un serio obstáculo para llevarse a término, pues al menos se suscitaría en la conciencia del actor la $d u d a$, y así, la conciencia de la posibilidad de no entrar en el juego ${ }^{28}$.

Mas a este conjunto de reflexiones quisiéramos añadir una conclusión más, y que ha estado presente, de un modo soterrado, en todo cuanto venimos diciendo: cabría afirmar que Hobbes defiende una concepción sacralizada del cuerpo, con claras consecuencias en el plano moral y político: un cuerpo que reclama libertad, en cuanto al contenido de la universal aspiración a la felicidad, y que, por tanto, exige del poder político libertad para definir el modo de entender qué sea una vida buena; pero también que reclama la puesta en marcha de políticas que hagan posible el desarrollo y concreción de las plurales concepciones del bien. Y todo ello en el contexto más amplio -y también demandado por una corporeidad que reclama una autoconservación lúcida- de la paz social y de la seguridad, que sólo puede nacer del respeto debido al pacto, y, por tanto, de la sujeción a la ley como criterio político definitorio de lo justo y de lo injusto, y como único marco de legitimidad donde pueden desplegarse las plurales concepciones del bien. Porque sólo articulando la inapelable exigencia de paz social con la libertad para definir las plurales concepciones de qué sea una vida buena, en el contexto de una justicia pública común, que pasa, como hemos visto, por el reconocimiento del valor sagrado del cuerpo de los destinatarios de la política; sólo integrando estos tres ámbitos, a saber, paz, libertad y justicia, no sesgaremos la

${ }^{27}$ Como muy bien lo ha visto Zarka, hay un conflicto, pero no una contradicción lógica, entre el derecho subjetivo del individuo frente al castigo, pues nadie está obligado a soportar la violencia del castigo, y, en este sentido, nadie está obligado a no resistirse; y, por otra, el derecho del Estado a castigar para salvaguardar el cumplimiento del pacto por parte de quienes no lo cumplan (ZARKA, 1997, p. 246-270). De la problematicidad de este planteamiento se ha hecho cargo Ryan (1996, p, 237-241).

${ }^{28}$ En relación con el tema de la moral en la guerra, y de la necesidad de evitar la crueldad en la misma, remitimos al clásico libro de M. Walzer, y en particular a propósito de la matanza de My-Ly (WALZER, 2003, p. 410s).

Revista Tópicos Educacionais, Pernambuco, v. 27, n. 02, p. 182-206, 2021. ISSN: 2448-0215.

https://periodicos.ufpe.br/revistas/topicoseducacionais/index

DOI: $10.51359 / 2448-0215.2021 .251832$ 


\section{REVISTA TóPICOS Educacionais \\ Revista do Programa de Pós-Graduação em Educação \\ da Universidade Federal de Pernambuco (UFPE)}

concepción política hobbesiana, que encuentra en nuestra común corporeidad el fundamento para una interpretación de su pensamiento en clave cosmopolita. Porque, a fin de cuentas, todos los seres humanos, en tanto que habitamos un mismo cuerpo, estaríamos demandando no solo la protección y desarrollo de nuestras vidas en el seno de los Estados, sino también en el de las relaciones internacionales. No cabe duda de que frente a particularismos y nacionalismos que desembocan en la violencia, tal horizonte, utópico pero necesario, encontraría una importante legitimación a partir de la esencia de lo político, tal y como lo entendemos en Hobbes.

Y ello teniendo presente, aplicable también a un horizonte cosmopolita, el hobbesiano par conceptual protección/obediencia, porque no debemos olvidar que nuestro cuerpo, o mejor, nuestra mortal y deficitaria corporeidad, es, en nuestro afán por lograr una autoconservación inteligente, la razón de ser de nuestra obediencia; pero también es, como hemos tenido ocasión de ver, la razónde ser de nuestra posible desobediencia. Y esto cabría aplicarlo, como decimos, no sólo en el ámbito del individuo y del Estado, sino en el de las relaciones estatales, y por tanto en un horizonte político cosmopolita.

Por último, hay que destacar una idea que nos parece esencial, a saber: que ni tiranías -con todo lo que de brutal opresión incorporan para nuestra encarnada racionalidad-, ni torturas, o arbitrariedades, sea cual sea el signo de regímenes que las practiquen; pero tampoco la escueta apelación a una libertad que, a cambio sólo de ofrecer seguridad, abandone a los ciudadanos a su propia suerte, tienen cabida, ni justificación alguna, en la hobbesiana concepción de lo político, tal y como la entendemos, donde Behemoth, sea cual sea la faz con la que pretenda mostrarse, debería estar definitivamente erradicado, porque como sentenció Jean Améry, dando testimonio del horror de la violencia sufrida en sus propias carnes,

Las fronteras de mi cuerpo son las fronteras de mi yo. La epidermis me protege del mundo externo: si he de conservar la confianza, sólo puedo sentir sobre la piel aquello que quiero sentir (AMÉRY, 2001, p. 191).

$\mathrm{Y}$ es evidente que nuestra piel, la de todos los que habitamos el cuerpo que somos, no quiere la indigencia, la privación de libertad, la tortura, la mutilación o la muerte. Y tal vez esta misma idea es la que, varios siglos antes, alentó a Hobbes a oponer a la violencia el contrato, y a precisar, como hemos tenido ocasión de ver detenidamente, los contornos del ejercicio legítimo del poder; así como delimitar a partir del hecho incontestable del cuerpo que somos, las no menos

Revista Tópicos Educacionais, Pernambuco, v. 27, n. 02, p. 182-206, 2021. ISSN: 2448-0215.

https://periodicos.ufpe.br/revistas/topicoseducacionais/index DOI: $10.51359 / 2448-0215.2021 .251832$ 


\section{REVISTA TóPICOS EDUCACIONAIS \\ Revista do Programa de Pós-Graduação em Educação \\ da Universidade Federal de Pernambuco (UFPE)}

esenciales cuestiones de la obediencia y desobediencia a aquél, cuyo esquema de pensamiento cabría trasladarlo no sólo al interior del Estado, sino también, y en buena lógica, a un horizonte político, tal vez utópico, pero necesario y universal, y, por ende, cosmopolita.

\section{Referencias}

AMÉRY, Jean. Más allá de la culpa y de la expiación. Tentativas de superación de una víctima de laviolencia. Valencia: Pretextos, 2001.

BADILLO, Pablo. Fundamentos de Filosofía Política. Madrid: Tecnos, 1998.

BATAILLE, George. El erotismo. Barcelona: Tusquets, 2000.

BATAILLE, George. El Estado y el problema del fascismo. Valencia: Pre-Textos, 1993.

BERLIN, Isaiah. Berlin, I. Isaiah Berlin en diálogo con Ramin Jahanbegloo. Madrid: Anaya \& Mario Muchnik, 1993.

BOBBIO, Norberto. Thomas Hobbes. Barcelona: Paradigma, 1990.

DE JULIOS, Alfonso. La dinámica de la libertad: tras las huellas del liberalismo. Sevilla: Universidad de Sevilla. Secretariado de Publicaciones, 1997.

DE JULIOS, Alfonso. En las encrucijadas de la modernidad: política, derecho y justicia. Sevilla: Universidad Sevilla. Secretariado de Publicaciones, 2000.

HEGEL, Georg Wilhelm Friedrich. Lecciones sobre la historia de la filosofía, III, México: FCE, $1^{\text {a }}$ reimp. 1977, p. 334.

HERMOSA, Antonio. La doctrina penal en Hobbes. Fragmentos de Filosofía, Núm. 6. 2008, pp. 81-103.

HERMOSA, Antonio. Sociedad natural y Estado en Hobbes. Fragmentos de Filosofía. Núm. 7, pp. 49-85.

HERNÁNDEZ, José María. El retrato de un dios mortal. Estudio sobre la filosofía política de Thomas Hobbes. Barcelona: Anthropos, 2002.

HOBBES, Thomas. Leviatán. Madrid: Alianza Universidad, 1989. Trad. Carlos Mellizo.

HOBBES, Thomas. El ciudadano. Madrid: Debate- CSIC. 1993. Ed. de J. Rodríguez Feo.

Revista Tópicos Educacionais, Pernambuco, v. 27, n. 02, p. 182-206, 2021. ISSN: 2448-0215.

https://periodicos.ufpe.br/revistas/topicoseducacionais/index

DOI: $10.51359 / 2448-0215.2021 .251832$ 


\section{REVISTA TóPICOS EduCACIONAIS \\ Revista do Programa de Pós-Graduação em Educação da Universidade Federal de Pernambuco (UFPE)}

HOBBES, Thomas. Behemoth. Madrid: Tecnos, 1992a. Ed. de M.A. Rodilla.

HOBBES, Thomas. Diálogo entre un filósofo y un jurista, y escritos autobiográficos. Madrid: Tecnos, 1992b, ed. de M.A. Rodilla.

HOBBES, Thomas. Elementos de Derecho Natural y Político. Centro de Estudios Constitucionales, 1979, Trad. de D. Negro Pavón, Madrid,

HABERMAS, Jürgen. Teoría y Praxis. Estudios de filosofía social. Madrid: Tecnos, 1987.

KANT, Inmanuel. De la relación entre teoría y práctica en el derecho político (Contra Hobbes), en Teoría y Práctica. Ed. de R. R. Aramayo, J. M. Palacios, y F. Pérez. Estudio preliminar de R. R. Aramayo. Madrid: Tecnos. Clásicos del pensamiento, 1986.

RYAN, Allan. Hobbes's political philosophy, en Sorell T. (ed.), The Cambridge Companion to Hobbes. Cambridge: Cambridge University Press, 1996, pp. 208-245.

ROSALES, José María. Política cívica. La experiencia de la ciudadanía en la democracia liberal. Madrid: Centro de Estudios Constitucionales, 1998.

SARAVIA, Gregorio. Thomas Hobbes y la Filosofía Política Contemporánea: Carl Schmitt, Leo Strauss y Norberto Bobbio. Madrid: Dykinson, 2011.

SARAVIA, Gregorio. Cuerpo y memoria: el ser físico ante la experiencia atroz. Daimon. Revista internacional de filosofía. $\mathrm{N}^{\circ}$ 5, 2016, pp. 765-774.

STRAUSS, Leo. La filosofía política de Hobbes: su fundamento y su génesis. Buenos Aires, Argentina: Fondo de Cultura Económica, 2006, Traducción de Silvana Carozzi.

TIERNO, Enrique. Estudio preliminar a Hobbes, Th., Del ciudadano y Leviatán. Madrid: Tecnos, $2^{\mathrm{a}}$ ed., 1991.

TÖNNIES, Ferdinand. Hobbes, vida y doctrina. Madrid: Alianza Universidad, 1988.

WALZER, Michael. Guerras justas e injustas. Barcelona: Paidós, 2003.

ZARKA, Yves. Hobbes y el pensamiento político moderno. Barcelona: Herder, 1997.

Recebido em 22 de setembro de 2021. Aprovado em 27 de setembro de 2021.

Revista Tópicos Educacionais, Pernambuco, v. 27, n. 02, p. 182-206, 2021. ISSN: 2448-0215. https://periodicos.ufpe.br/revistas/topicoseducacionais/index DOI: $10.51359 / 2448-0215.2021 .251832$ 